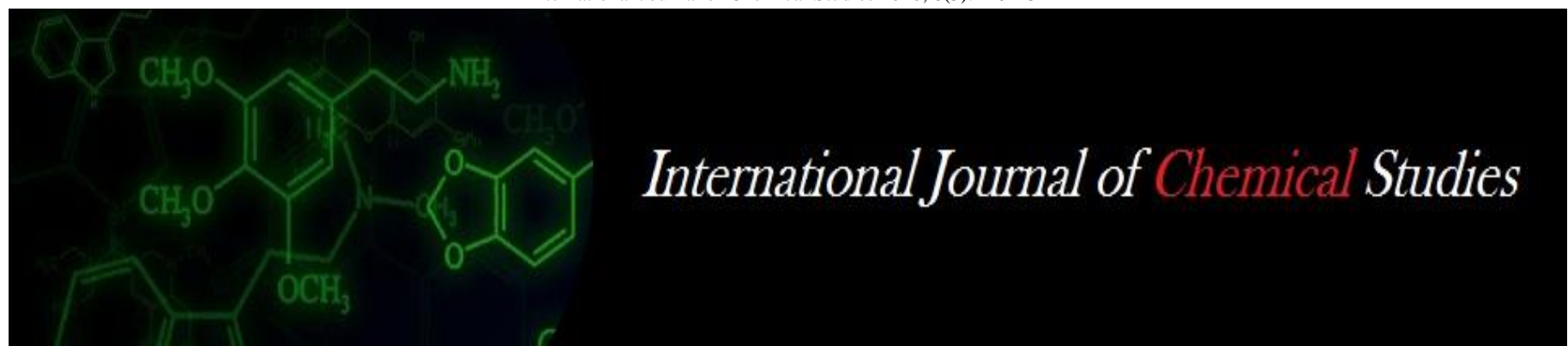

P-ISSN: 2349-8528

E-ISSN: 2321-4902

www.chemijournal.com

IJCS 2020; 8(3): 229-231

(C) 2020 IJCS

Received: 28-03-2020

Accepted: 30-04-2020

MV Swamy Babu

PG Student, Dept of Veterinary

Surgery and Radiology,

College of Veterinary Science,

Tirupati, Andhra Pradesh, India

$P$ Veena

Professor, Dept of Veterinary

Surgery and Radiology,

College of Veterinary Science,

Tirupati, Andhra Pradesh, India

RV Suresh Kumar

Professor and Univ. Head, Dept

of Veterinary Surgery and

Radiology,

College of Veterinary Science,

Tirupati, Andhra Pradesh, India

P Amaravathi

Asst. Prof, SLDL Dept of

Veterinary Pathology

College of Veterinary Science,

Tirupati, Andhra Pradesh, India

G Vani

Asst. Prof, Dept of Veterinary

Surgery and Radiology,

College of Veterinary Science,

Tirupati, Andhra Pradesh, India

Corresponding Author:

MV Swamy Babu

PG Student, Dept of Veterinary

Surgery and Radiology,

College of Veterinary Science,

Tirupati, Andhra Pradesh, India

\section{Efficacy of ivermectin and Tarantula cubensis extract in the treatment of bovine teat papillomatosis}

\author{
MV Swamy Babu, P Veena, RV Suresh Kumar, P Amaravathi and G \\ Vani
}

DOI: https://doi.org/10.22271/chemi.2020.v8.i3c.9231

\begin{abstract}
The objective of this study was to examine the effectiveness of ivermectin and Tarantula cubensis extract in the treatment of teat papillomas in cattle. The present clinical study was conducted on 12 cows with papillomatosis. The animals were divided in to two groups of six animals each and were treated with ivermectin and Tarantula cubensis extract respectively. Three animals in group I and six animals in group II responded well to the treatment. The results of the study revealed that Tarantula cubensis extract was found to be efficacious in the treatment of bovine papillomatosis than ivermectin with no occurrence for a period of 6 months.
\end{abstract}

Keywords: Bovine teat papilloma, ivermectin Tarantula cubensis extract

\section{Introduction}

The bovine papillomatosis is an infectious, contagious and neoplastic disease characterized by the presence of multiple, benign tumours (Papillomas) that can regress spontaneously or progress to malignant neoplasms. It is a significant disease related o udder health. It is instigated by oncogenic Bovine papilloma viruses (BPV) which are non enveloped icosahedral viruses, $50-55 \mathrm{~nm}$ in diameter, with a circular, double stranded DNA genome ranging from 7.4 to $8.6 \mathrm{~kb}$ (Somvanshi, 2011) ${ }^{[12]}$. It can be exhibited as benign nodular lesions, finger like projections or cauliflower like small growths on the skin arising from stratified squamous epithelium that may appear solitary or in multiples.

Different treatment options like homeo drug thuja in cattle (Veena, 2001) ${ }^{[13]}$, fig tree latex in cattle (Hemmatzadeh et al., 2003) ${ }^{[6]}$, and bai-mast herbal capsules (Kumar and Pant, 2017) ${ }^{[10]}$ were tried in clinically affirmative cases of papillomatosis without agreement in efficacy.

The anthelmintic, ivermectin, was used commonly in cattle for the treatment of parasitism. It was clear that the immune system plays an important role in modulating the severity of papillomas. Ivermectin stimulate the humoral and cellular immunity. Ivermectin increases antibody production, T- lymphocytes and macrophages dependent response and therefore had an immunomodulator effect.

The extract of Tarantula cubensis is a homeopathic drug used widely in veterinary medicine. It is effective through the spider venom it contains. Tarantula cubensis extract is used to treat foot and hoof rot. Tarantula cubensis extract stimulate the absorption and demarcation of many types of ulcers and necrosis as well as treating mammary gland tumors and proliferative cases in animals (Gultiken and Vural 2007 and Gultiken et al., 2015 in canine mammary tumors, Icen et al., 2011 in canine oral papillomatosis) ${ }^{[4,5,7]}$

Although many methods are used to treat papillomatosis, many of them are difficult and cumbersome to implement. For this reason the objective of his study was to examine the effectiveness of ivermectin and Tarantula cubensis extract in the treatment of teat papillomas in bovines.

\section{Materials and Methods}

The present study was carried out on the clinical cases presented to Department of Veterinary Surgery and Radiology, Teaching Veterinary Clinical Complex of SVVU, Tirupati and also 
cases presented to the hospitals in and around Tirupati over a period of one year. The study materials consisted of 12 cows with papillomatosis and were divided in to two groups of six animals each.

Group I - Animals were given ivermectin @ 200 mcg/ kg b.wt subcutaneously at 15 days intervals.

Group II - Animals were administered Tarantula cubensis extract $10 \mathrm{ml}$ subcutaneously at weekly intervals for two weeks.

The initiation of treatment was considered as day 00 and the animals were monitored every 15 days up to 90 days and the healing process of the papilloma was recorded.

\section{Results and discussion}

Out of 6 cases, 3 animals responded well to ivermectin thus giving efficacy in only $50 \%$ of cases. Warts disappeared between 45 - 60 days after the second injection (Fig 1). (Jameel et al. 2011, Jana and Mukherjee 2013 and Feyisa 2018) ${ }^{[8,9,3]}$.

In group II, a decrease in size and drying and shrinking of the papillomas were observed in all the animals after 15 days of treatment. The efficacy of the treatment was $100 \%$ with no recurrence for a period of 6 months (Fig 2).

In our study, improvement obtained upon subcutaneous injections of ivermectin for the treatment of papillomatosis might have occurred due to immunostimulatory effect of ivermectin (Jameel et al., 2011) ${ }^{[8]}$. Low success rate in our study was probably due to the fact that ivermectin did not stimulate the immune system of these animals sufficiently (Borku et al., 2007) ${ }^{[1]}$.

In this study, Tarantula cubensis extract was found to be effective in decreasing clinical lesions in bovine teat papillomatosis and the post treatment observations for 6 months. Papillomas regression was verified after the second week evidenced by papillomas necrosis, detachment and fall. There was no recurrence in any animal, with no adverse reaction. Although the mechanism of action of Tarantula cubensis extract was not completely clear, it is thought to stimulate the defence mechanism of the body to aid spontaneous remission (Cam et al., 2007) ${ }^{[1]}$. Similar findings were reported by Paksoy et al. (2015) ${ }^{[11]}$ who used Tarantula cubensis extract for the treatment of bovine teat papillomatosis.

On the basis of our results, the success rate of bovine teat papillomatosis through Tarantula cubensis extract was higher than ivermectin. Due to the ease of use and availability in preparatory form it is concluded that Tarantula cubensis extract can be used in the treatment of bovine teat papillomas effectively under field conditions.

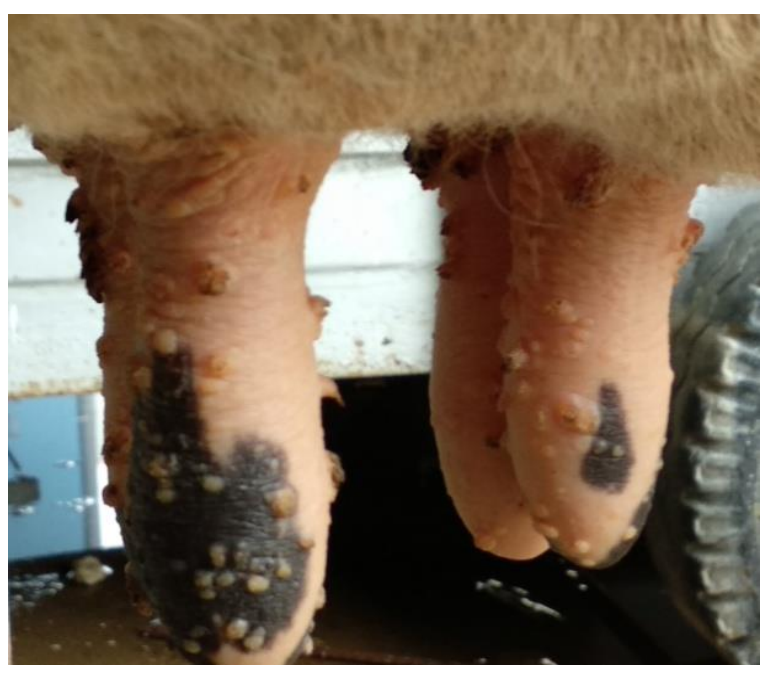

Before Treatment

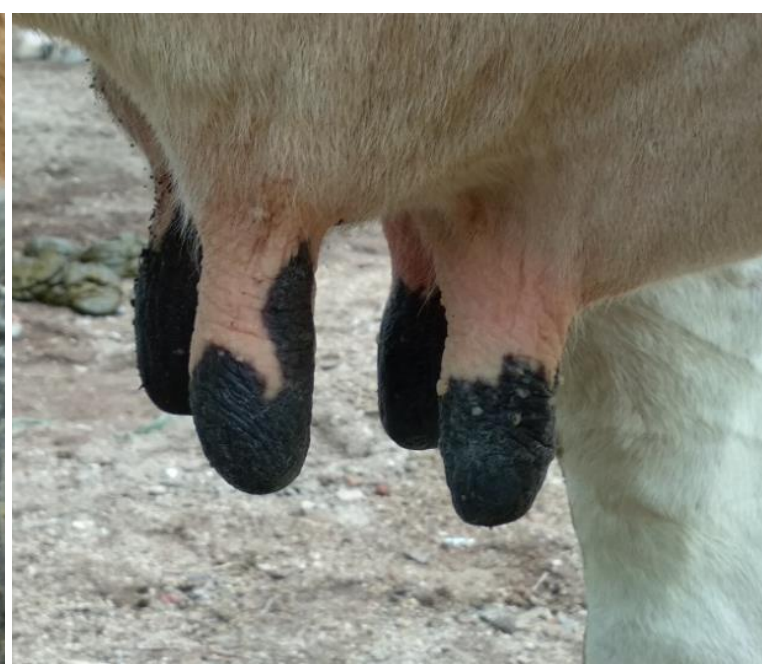

After Treatment

Fig 1: Animals treated with Ivermectin

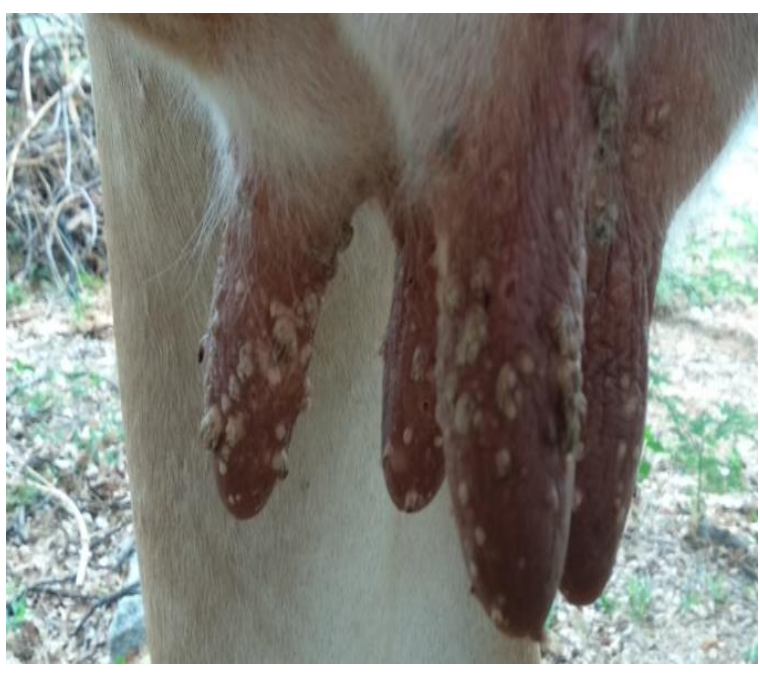

Before Treatment

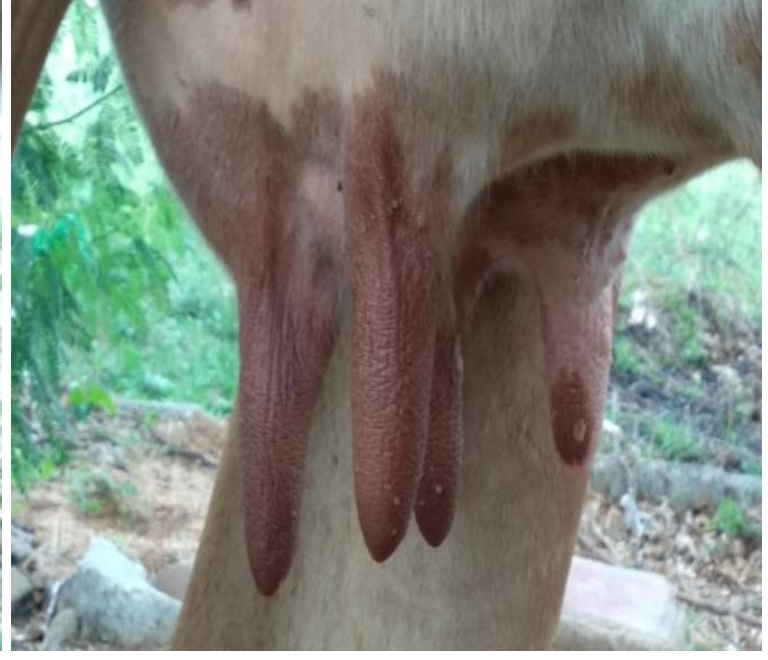

After Treatment

Fig 2: Animals treated with Tarantula cubensis extract 


\section{References}

1. Borku MK, Atalay O, Kibar M, Cam Y, Atasever A. Ivermectin is an effective treatment for bovine cutaneous papillomatosis. Research in Veterinary Science. 2007; 83:360-363.

2. Çam Y, Kibar M, Atasever A, Atalay O, Beyaz L. Efficacy of levamisole and Tarantula cubensis venom for the treatment of bovine cutaneous papillomatosis. Veterinary Record. 2007; 160:486-488.

3. Feyisa AF. Cutaneous bovine papillomatosis (warts) treatment outcome using ivermectin: a case of crossbred heifer and calf. Journal of Veterinary Science and Technology. 2018; 9(2):544.

4. Gültiken N, Vural MR. The effect of Tarantula cubensis extract applied in pre and post operative period of canine mammary tumors. Journal of Istanbul Veterinary Sciences. 2007; 2:13-23.

5. Gultiken N, Guvenc T, Kaya D, Agaoglu AR, Ay SS, Kucukaslan I, Emre B et al. Tarantula cubensis extract alters the degree of apoptosis and mitosis in canine mammary adenocarcinomas. Journal of Istanbul Veterinary Science. 2015;16(2):213-219.

6. Hemmatzadeh F, Fatemi A, Amini F. Therapeutic effects of fig tree latex on bovine papillomatosis. Journal of Veterinary Medicine Berlin. 2003; 50:473-476

7. Icen H, Sekin S, Simsek A, Kochan A, Tunik S. The efficacy of Tarantula cubensis extract (Theranekron) in treatment of canine oral papilloma. Asian Journal of Animal and Veterinary Advances. 2011; 6(7):744-749

8. Jameel GH, Jawad SJ, Ebraheem TA, Majeed WA. Study of ivermectin effect on the bovine warts. Diyala Journal for Pure sciences. 2011; 7(2):117-126.

9. Jana, Mukherjee. Jana D and Mukherjee S K 2013 Therapeutic management of bovine cutaneous papillomatosis with ivermectin in farm bred calf crops of West Bengal India. Exploratory Animal and Medical Research. 2013; 3(2):123-130.

10. Kumar M, Pant SS. Herbal Therapy: An alternative against bovine teat papillomatosis in cattle. International Journal of Current Microbiology and Applied Sciences. 2017; 6(2):1194-1196.

11. Paksoy Z, Gulesci N, Kandemir FM, Dinçel GC. Effectiveness of levamisole and Tarantula cubensis extract in the treatment of teat papillomatosis of cows. Indian Journal of Animal Research. 2015; 49(5):704-708.

12. Somvanshi R. Papillomatosis in buffaloes: A less-Known Disease. Transboundary and Emerging Diseases 2011; 58:327-332.

13. Veena P. Homeopathic treatment of papillomatosis in a Jersey cow. Indian Veterinary Journal. 2001; 78:7. 